caput-coli is enlarged, in the latter it is contracted; in the one the symptoms are allied to chronic dysentery, in the other to intuseusception.

Beverley, Yortshire, Angust 14th, 1855.

\section{DISLOCATION OF THE FEMUR ON THE DORSUM OF THE ILIUM, REDUCED EIGHT MONTHS AFTER DISARTICULATION.}

By H. F. GISBORNE, Esq., Surgeon to the Derbyslire General Infirmary.

Wruhrax Woodras, aged 45, of Newborough, Staffordshire, was admitted into the Derbyshire Infirmary, on the 1st of August, 1855, under my care, for a supposed prolonged case of sciatica. It appears that on the 20th of December, 1854, in crossing over a wooden bridge, he put his foot into a hole, got his body twisted, and fell. Surgical aid was obtained; but the nature of the accident not being correctly ascertained, he was leeched and blistered, etc., and continued under treatment for several months; as a last resource, he was sent to the hospital. On examination, the right thigh was partially flexed, and bent over the opposite limb, the toes resting on the instep of the other foot; the leg was shortened upwards of three inches, and was wasted from inaction; the head of the femur was distinctly felt on the ileum, but very little motion could be perceived. Woodings' general health seemed declining from treatment and confinement.

A consultation was called; and it was deemed right to attempt reduction.

On the 7th of this month, Woodings, under the influence of chloroform, had his thigh freely bent and rotated, to detach some of its new connections; gradual extension with pulleys was then made, and, in about fifteen minutes, it returned to its socket with an audible noise. The limb rotated, but the trochanter seemed to project more than the left one; this probably arose from the altered position and emaciation of the neighbouring muscles, and not improbably in part from the acetabulum having some deposit of new matter in it. The limb measured the same length as its fellow one; it was secured for some days with the long splint, and is now (August 18th) merely supported by a belt round the pelvis.

This case is altogether progressing most satisfactorily ; and is so far very encouraging to surgeons to attempt the replacement of dislocations after lengthened periods.

Derby, August 19, 1855.

\section{CASE OF A MAN SWALLOWING A HALF- SOVEREIGN.}

By G. MALLETT, Esq.

Ox the 17th of this month, a man, aged 26 years, put into his mouth a half-sovereign; a child play fully attempting to seize it, caused him to throw back his head; and, by so doing, the piece of money was precipitated into the larynx. Mr. Eames, an intelligent practitioner in the neighbourhood, was immediately sent for, and, finding such to be the case, requested further assistance. I was then summoned, and saw the patient about four hours after the accident

The man was breathing calmly and naturally; he had no wheezing, cough, or other distressing symptoms; but he said be felt an uneasiness about an inch below the thyroid cartilage; and, on placing the stethoscope over that portion of the trachea, a decided whistling in the respiration was heard. Taking into consideration the absence of all irritation, and in fact of all distressing symptoms, we decided that we should not be justified in opening the trachea until some cough and irritation had come on, in the hopes that the cough might be sufficient to dislodge the foreign body.

August 20th. He was much the same, except that the breathing was a little more whistling, accompanied with a alight degree of fever.
Angust 21st. $\triangle$ fit of coughing came on. Ho wh directed to put his head lower than the body, and the half sorereign was ejected by the cough. He has hid no unpleasant feeling since, and is in fact quite well.

RExakRs. I think the result proves that we were justified in deferring the operation-an operation cady enough to perform, but which is often attended with fatal results, either owing to the immediate effects of the operation, or more probably to the incurable nature of the disease for which it is performed.

Bolton-le-Moors, August 22nd, 1855.

\section{PFRISCOPIC REVIFW.}

\section{PRAGTTE OF MTEDTCITE ATD PATHOLOGY.}

\section{GLEANINGS FROM THE JOURNALS.}

\section{PATHOLOGY AND TREATHENT OF BERIBERI.}

Dr. Morenfad regards beriberi as a general dropsy of a complicated character, for the most part appearing when the vessels are tolerably full of blood, and a blood abounding in watery constituent, and following exposure to external cold. $\mathrm{He}$ is of opinion that the term ought to be expunged from medical literature, as likely to mislead by its indefiniteness and he now seeks to remove some of the difficulties enveloping the subject by reducing it to known conditions.

$\mathrm{He}$ finds these conditions in the scorbutic diathesis. $\mathrm{He}_{\theta}$ believes that the disease, more "particularly in its acute form, will be found to present itself in individuals favourably circumstanced for the development of a scorbutic taint, and who, while in this diathesis, have been exposed to the sudden cooling of the surface of the body from sudden alternations of tem. perature or of wet." Regarding the disease as one of general dropsy, Dr. Morehead suggests that the principles to be followed in its treatment should be the same as those guiding the treatment of general dropsy. According to this view, he explains the apparently conflicting statements made by rarious authors, of the advantage of the most opposite kind of treatment. Dr. Morehead admits the occurrence of cases justifying antiphlogistic treatment; but in the majority of instances, diuretics, stimulants, and vapour baths, are required. Four cases are brought forward, which confirm the views of Dr. Morehead, both by their previous history, the course of the disease, and the post mortem appearances. The persons affected were sailors, who, during an unexpectedly extended voyage, had been restricted to a poor diet, and much exposed to inclemency of the weather; while all those who in the same ship had been supplied with antiscorbutic food, had escaped the disease. The symptoms were œdema of the lower extremities, cansing a waddling gait, feeble pulse, scanty urine (not albuminous), uneasiness at epigastrium, moist tongue, gums dis coloured but not swollen. The post mortem examination of two of the cases exhibited fluidity of the blood, and congestion of the liver; but no organic disease of any of the viscera. There was some serous effusion in the arachnoid, pleura, and peritoneum. (Trans. of Med. and Phys. Soc. of Bombay; and Brit. and For. Med.-Chir. Review, July 1855.)

ETIOLOGY OF ELEPHANTIASIS ARABUY.

Dr. Rigner, in the Zeitschrift der $K . K$. Gesellschaft der Aerzte zu IVien, Heft 1, 1855, endeavours to show that ele phantiasis is not essentially a disease of tropical climates, but that it may occur sporadically all over the globe, provided certain circumstances affect the patient by which the functions of the vascular system, and especially of the lymphatics, are impaired. To an alteration of the functions of the latter, he attributes the hypertrophy of the cellalar tissue and of the skin which constitutes the chief feature of the disease. In fow cases of elephantiasis of a lower extremity, the commencement of the affection, which he always observed on the left side only, was marked by induration and swelling of the inguinal glands, indicating an arrest of their normal function. The author compares the disease to phlegmasia alba dolens, and to sclerosis neonatorum, which Henle has attributed to an extensive insufficiency of the lymphatics. In two adult healthy Turls that came under Dr. Rigler's notice, the disease, affecting their left feet, followed the occurrence of plague buboes. A case of 